\title{
A stochastic space-time rainfall forecasting system for real time flow forecasting II: Application of SHETRAN and ARNO rainfall runoff models to the Brue catchment
}

\author{
D. Mellor ${ }^{1}$, J. Sheffield ${ }^{1}$, P.E. O'Connell ${ }^{1}$ and A.V. Metcalfe ${ }^{2}$ \\ ${ }^{1}$ Water Resource Systems Research Laboratory, Department of Civil Engineering, University of Newcastle upon Tyne, Newcastle upon Tyne, \\ NE1 7RU, UK \\ ${ }^{2}$ Department of Engineering Mathematics, University of Newcastle upon Tyne, Newcastle upon Tyne, NE1 7RU, UK \\ e-mail for corresponding author: P.E.O'Connell@newcastle.ac.uk
}

\section{Abstract}

Key issues involved in converting MTB ensemble forecasts of rainfall into ensemble forecasts of runoff are addressed. The physically-based distributed modelling system, SHETRAN, is parameterised for the Brue catchment, and used to assess the impact of averaging spatially variable MTB rainfall inputs on the accuracy of simulated runoff response. Averaging is found to have little impact for wet antecedent conditions and to lead to some underestimation of peak discharge under dry catchment conditions. The simpler ARNO modelling system is also parameterised for the Brue and SHETRAN and ARNO calibration and validation results are found to be similar. Ensemble forecasts of runoff generated using both SHETRAN and the simpler ARNO modelling system are compared. The ensemble is more spread out with the SHETRAN model, and a likely explanation is that the ARNO model introduces too much smoothing. Nevertheless, the forecasting performance of the simpler model could be adequate for flood warning purposes.

Keywords: SHETRAN, ARNO, HYREX, rainfall-runoff model, Brue, real-time flow forecasting

\section{Introduction}

\section{OBJECTIVE}

The primary objective of the work described in this second paper is to develop a catchment runoff forecasting system which provides an ensemble of hydrograph scenarios rather than a single uncertain estimate. For example, the additional information could be used in a flood warning scheme, by allowing operational decisions to be made on the basis of a probability distribution of possible flood losses. The predicted rainfall field is by far the most significant component of the uncertainty. A method for generating an ensemble of rainfall fields, consistent with radar observations at the time of the forecast, was presented in Mellor et al. (2000). This paper is concerned with rainfallrunoff modelling and flow forecasting, and with optimizing the forecasting technique with respect to forecasted runoff. The SHETRAN physically-based distributed modelling system has been employed to address a number of key issues in this regard: firstly, what impact is the spatial averaging of rainfall likely to have on the accuracy of runoff forecasts, and, secondly, how useful are ensemble forecasts of runoff generated from the MTB ensemble forecasts of rainfall? The answers to these questions are the key to finding the optimal trade-off between accuracy and computation time for the MTB system in a real-time environment. The ARNO modelling system, widely used for real-time flow forecasting, has also been employed to generate ensemble forecasts of runoff, which, when compared with SHETRAN ensemble forecasts, allow the impact of a simpler model and a lumped rainfall input on the ensemble forecast to be assessed.

\section{REVIEW OF RELATED WORK}

Spatial variability occupies a central role in understanding how catchments respond to rainfall. Spatially and temporally varying rainfall inputs interact with spatially varying catchment characteristics (topography, soils, vegetation, geology) to produce spatially and temporally varying soil moisture and runoff fields. Rainfall varies across a range of scales (local convective storms to large scale frontal systems), and so attempts to understand the influence of spatial variability in rainfall on catchment response must recognise the interaction between the scale of rainfall variability and the catchment scale. In an analytical study, Milly and Eagleson (1988) investigated cases where the storm size is similar to the modelled area. They concluded 
that, in general, spatially variable rainfall produces increased surface runoff in comparison with spatially uniform rainfall of the same value. Several studies of the effects of spatial sampling and averaging have employed observations from dense networks and/or simulated rainfall fields. Bras $e t$ al. (1988) carried out an extensive simulation study and provided guidelines for the optimum number of raingauges and sampling intervals for rainfall and streamflow records, for a given cost, as a function of catchment parameters. Krajewski et al. (1991) used a rainfall field model in conjunction with a distributed rainfall-runoff model to investigate rainfall sampling strategies for a small catchment $\left(7.5 \mathrm{~km}^{2}\right)$ in Iowa. Results were assessed by comparison with 'ground truth', which was chosen to be the response obtained from the distributed model with a rainfall input 'sampled' from the rainfall field model at 87 'gauges'. A rainfall input based on a single gauge was found to give a good approximation to the response but would occasionally, even in this small catchment, miss a storm altogether. Shah et al. (1996) carried out a similar study in a $10.55 \mathrm{~km}^{2}$ catchment subjected to frontal rainfall storms. The results suggested that, under 'wet' conditions, good predictions of runoff can be obtained with a spatially averaged rainfall input, provided at least one raingauge is available in the $10.55 \mathrm{~km}^{2}$ catchment. However, for 'dry' catchment conditions, the runoff prediction errors were considerably larger than for the wet case, suggesting that there is interaction between the spatial variability in rainfall and the spatial distribution of soil moisture which controls runoff production.

Michaud and Sorooshian (1994) investigated the effects of spatial averaging of thunderstorms over a semi-arid catchment at Walnut Gulch in Arizona. They found that the effect of averaging data from a very dense network of raingauges $\left(1\right.$ per km$\left.{ }^{2}\right)$ over $4 \mathrm{~km} \times 4 \mathrm{~km}$ squares was to reduce the peak flow, simulated with the KINEROS rainfall-runoff model (Goodrich, 1990), by an average of $34 \%$. The current spatial resolution of radar precipitation estimates in the South-Western United States, then used in the ALERT real time flash flood forecasting system, was $4 \mathrm{~km}$ by $4 \mathrm{~km}$ squares. Michaud and Sorooshian (1994) concluded that this resolution may not be sufficient to produce reliable rainfall-runoff forecasts in midsized catchments subject to localised thunderstorms and large infiltration losses. Obled et al. (1994) investigated the sensitivity to spatial rainfall patterns of a rainfall-runoff model (TOPMODEL) for a catchment of $71 \mathrm{~km}^{2}$, and found that knowledge of spatial pattern, in addition to the total volume of rainfall, did not improve noticeably runoff predictions.

From the results summarized above, it is apparent that unanimous agreement does not exist concerning the importance of spatial variability of rainfall in controlling catchment response. Clearly, each set of results is conditional on a particular rainfall regime, a particular catchment and a particular rainfall-runoff model. Different conclusions can be expected to apply for convective rainfall as compared to frontal rainfall, and to models where different degrees of spatial lumping are adopted.

\section{Application of SHETRAN to the Brue catchment}

\section{THE SHETRAN MODEL STRUCTURE}

SHETRAN is a physically-based spatially distributed modelling system for water flow, sediment transport and contaminant migration, applicable at the catchment scale. It is based on an enhanced version of the Systeme Hydrologique Europeèn (SHE) hydrological modelling system (Abbott et al., 1986), which provides an integrated surface and subsurface representation of water movement through a river basin, incorporating the major elements of the land phase of the hydrological cycle (interception, evapotranspiration, snowmelt, overland and channel flow, unsaturated and saturated zone flow) (Fig. 1). Each of the hydrological processes is modelled either by finite difference representations of the partial differential equations of mass and energy conservation or by empirical equations derived from independent experimental research. The spatial distribution of catchment parameters, rainfall input and hydrological response is achieved in the horizontal direction through the representation of the catchment by an orthogonal grid network and in the vertical direction by a column of horizontal layers at each grid square.

Meteorological inputs to the catchment are determined as a function of precipitation falling as rain or snow, measured or calculated potential evapotranspiration and heat budgets used in calculating rates of snowmelt. Net precipitation to the ground surface is calculated from incoming precipitation and snowmelt, with allowance for interception, evaporation and drainage from a vegetation canopy. Actual rates of evapotranspiration are calculated as a function of dynamic soil moisture conditions. Evaporation rates from leaf surfaces of the vegetation, from the soil surface, and from free water surfaces are calculated. Infiltration into the ground surface occurs either from a net precipitation flux or from surface water. Distribution of soil moisture content and tension in the unsaturated zone, and recharge to the saturated zone, are calculated. Saturated zone flows are calculated for a heterogeneous, anisotropic, unconfined aquifer. Exchange flows between the aquifer and a partly penetrating channel are computed, with or without a low permeability channel lining.

Surface water is generated by either infiltration excess or saturation excess mechanisms, and is routed into the channel as sheet overland flow. Channel routing takes place through the channel network, through variable crosssection channel reaches, connected in any topology (distributaries as well as tributaries can be included, allowing looped networks). Backwater effects and overbank flooding can be modelled, but at a level relevant to 


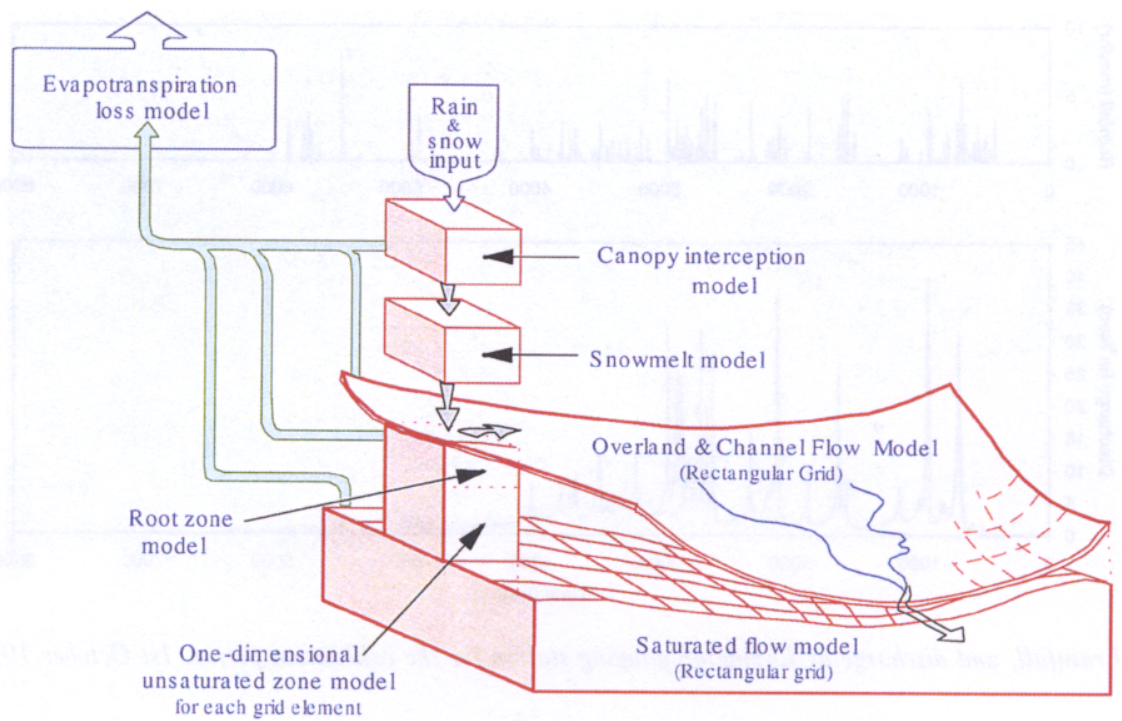

Fig. 1. Schematic of the SHE hydrological modelling system.

catchment modelling. Additional sources and sinks to the channel are from aquifer exchanges through the channel bed and bank, direct infiltration and evaporation at a dry channel bed, and direct extraction of channel water by plants.

\section{MODEL IMPLEMENTATION ON THE BRUE}

A high resolution SHETRAN model of the Brue catchment was set up as a test bed to explore the issues identified above. As SHETRAN is a physically based, distributed model it has large data requirements. Hydrometeorological and spatial topographic, soil and vegetation data were obtained from various sources to represent the spatial distribution of the catchment as a network of 2,176 $(250 \mathrm{~m} \times 250 \mathrm{~m})$ SHETRAN grid elements. Grid elevations were derived from a $50 \mathrm{~m}$ resolution digital elevation map (DEM), generated from Ordnance Survey (OS) 1:50,000 maps. Elevations ranged from $23 \mathrm{~m}$ at the outlet to $260 \mathrm{~m}$ at the eastern watershed. A combination of the DEM and a digitised river map was used to produce a channel network of 431 links which run along the edges of the grid elements (Fig. 2(a)). Soil and geological data required by SHETRAN include the spatial distribution of soil type (lateral and vertical), depth to impermeable bed and soil hydraulic properties. The spatial distribution of soil type across the Brue was obtained from a $100 \mathrm{~m}$ resolution map, from the Soil Survey and Land Research Centre (SSLRC). Utilising soil survey literature and geological and topographic data, likely occurring soil series were determined from the soil association distribution. Representative soil profiles for each soil series were obtained from the soil survey literature to
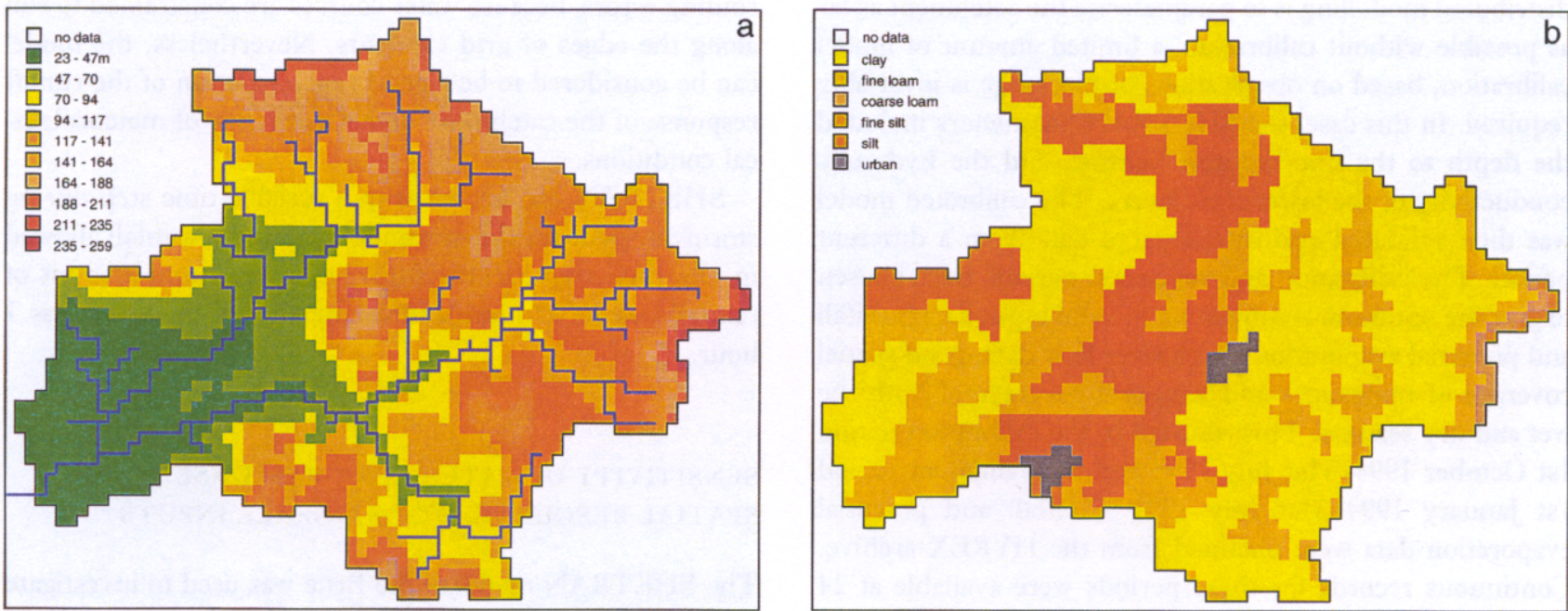

Fig. 2. (a) Elevation and river network used in the model of the Brue catchment. (b) Soil types used in the model of the Brue catchment. 

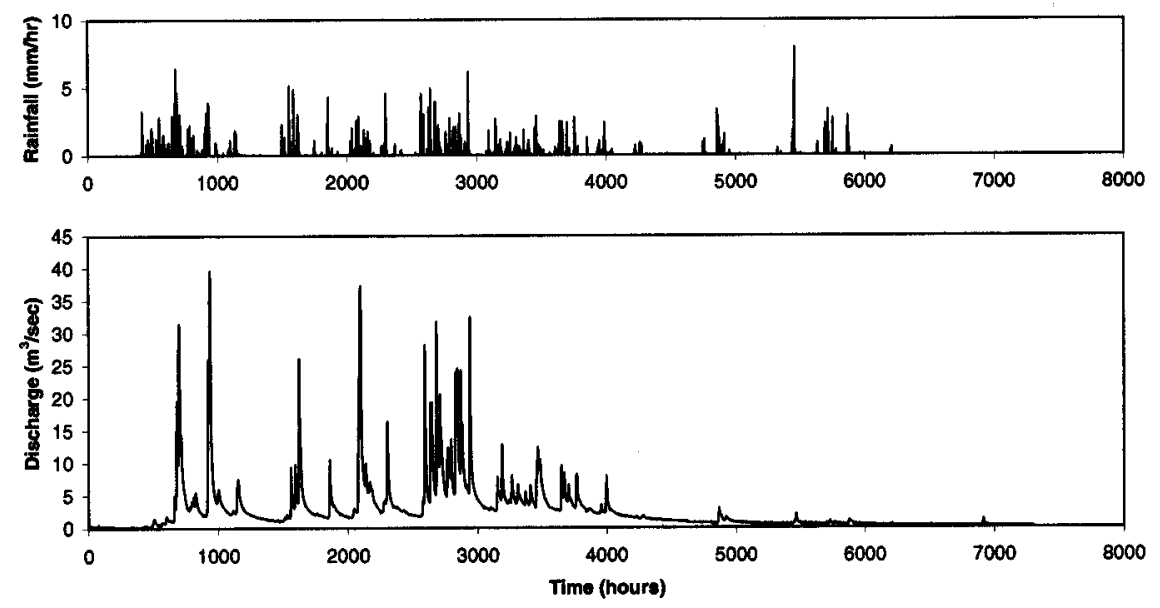

Fig. 3. Catchment total rainfall, and discharge at Lovington gauging station for the calibration period, 1st October 1994 until 31 st 7 uly 1995.

give vertical soil layer profiles with corresponding texture and bulk density values and organic content based on land cover. This resulted in a detailed 3-dimensional picture of the soils of the catchment with 143 different soil types and 95 different soil layer profiles (Fig. 2(b)). Soil water retention and hydraulic properties for each soil layer were then derived from texture, bulk density and organic matter content values using the methods of Brooks-Corey and Van Genuchten (Rawls and Brakensiek, 1989).

Land cover for each grid element was obtained from the $25 \mathrm{~m}$ resolution land cover map of Great Britain, maintained by the Institute of Terrestrial Ecology (ITE). This was reclassified according to hydrological behaviour to give 8 different land cover classes. Vegetation parameters describing leaf area index, leaf and stem drainage, interception storage, evapotranspiration properties and root distribution were extracted from the literature, and from previous UK applications of SHETRAN, and allocated to each land cover class.

Although the objective in SHETRAN physically based distributed modelling is to parameterise the catchment as far as possible without calibration, a limited amount of model calibration, based on observations of discharge is invariably required. In this case, the SHETRAN parameters included the depth to the impermeable bedrock and the hydraulic conductivity of the lower rock layers. The calibrated model was then validated against discharge data from a different period. The calibration and validation periods were chosen to give the optimum combination of valid input data (rainfall and potential evaporation), with river flow data, good spatial coverage of raingauges and temporal coverage of both the wet and dry seasons. This resulted in the calibration period 1st October 1994-31st July 1995 and the validation period 1st January 1994-31st July 1994. Rainfall and potential evaporation data were obtained from the HYREX archive. Continuous records for these periods were available at 24 gauges ( $0.2 \mathrm{~mm}$ tipping bucket) from the dense raingauge network of 49 gauges operating in the Brue. Thiessen polygons were used to assign rainfall time series to grid elements and hence as rainfall inputs to SHETRAN. Potential evaporation was taken from daily values calculated from meteorological data measured at the single automatic weather station in the catchment. Time series of catchment total rainfall and observed catchment discharge for the calibration period are shown in Fig. 3. For all simulations, a run-in period of 1 month was used to ensure stable soil moisture conditions. For the calibration period, good agreement was obtained between the simulated outlet discharge and observation (Fig. 4(a)). This can be quantified by an $R^{2}$ goodness of fit statistic (Nash and Sutcliffe, 1970) which equalled 0.91 for the calibration period. Application of the model to the validation period resulted in an $R^{2}$ of 0.89 (Fig. 4(b)), indicating that a robust model of catchment response has been obtained. The plots of errors, which are defined as the differences between observed flows and the SHETRAN simulated flows, emphasise the discrepancies. The sharp peak and trough combinations are due to slight differences in timing. These are likely to be due to stream routing errors, because water courses are constrained to run along the edges of grid elements. Nevertheless, the model can be considered to be a good representation of the runoff response of the catchment under this range of meteorological conditions.

SHETRAN can be run with a variable time step during storms by defining the maximum amount of rainfall allowed in one time step. In this study, this maximum amount of rainfall was set at $1 \mathrm{~mm}$ and the maximum time step was 1 hour.

\section{SENSITIVITY OF CATCHMENT RESPONSE TO THE SPATIAL RESOLUTION OF RAINFALL INPUTS}

The SHETRAN model of the Brue was used to investigate the sensitivity of the catchment response to the spatial resolution of rainfall inputs, as a function of initial soil 

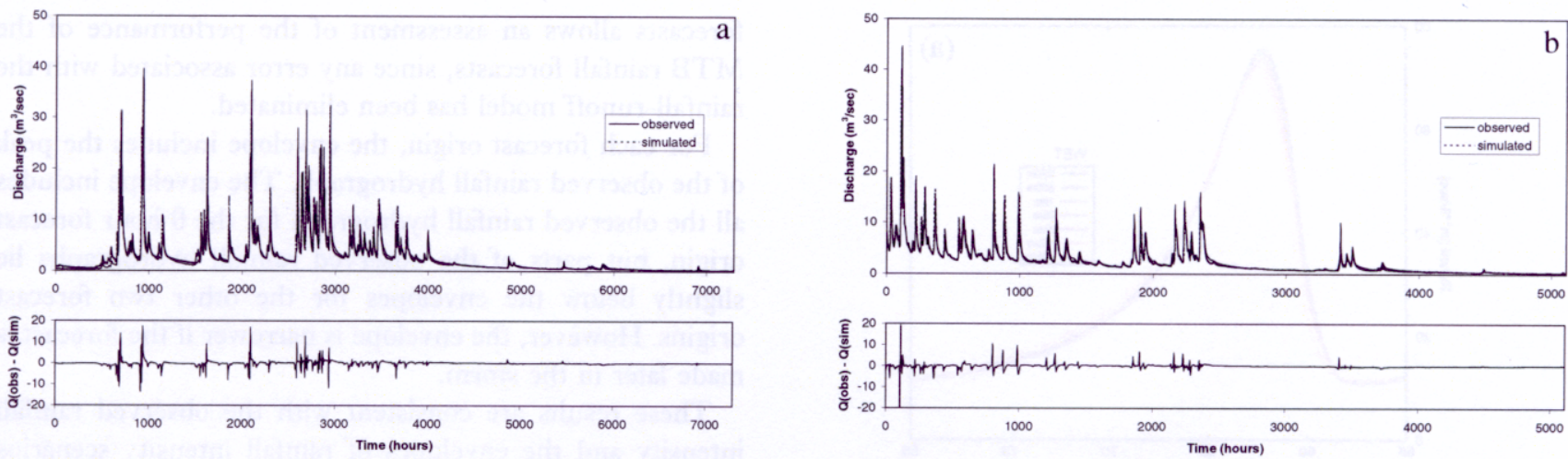

Fig. 4. (a) SHETRAN simulated outlet discharge, and observed discharge, at Lovington for the calibration period, 1st October 1994 until 31 st 7 uly 1995. (b) SHETRAN simulated outlet discharge, and observed discharge, at Lovington for the validation period, 1st fanuary 1994 until 31 st 7 uly 1994.

moisture conditions. Experiments were carried out for both synthetic and real radar data, the former providing a full test of sensitivity to spatial resolution, as synthetic data can be generated in the continuum of space (and time) by the MTB model. A limited sensitivity analysis was performed using real radar data measured at $5 \mathrm{~km}$ resolution.

A stochastic rainstorm was generated using the MTB model and synthetic radar data were extracted at the spatial resolution of the SHETRAN model of the Brue $(250 \mathrm{~m})$. A typical MTB storm over the Brue catchment is shown in Figs. 5(a)-(d). These synthetic radar data were put through the model under different initial soil moisture conditions to produce corresponding runoff responses. For the purpose of the sensitivity analyses, these were considered to be the precise responses for each initial condition. The initial soil moisture conditions, ranging from near saturation to very dry, were derived by setting the phreatic surface to a fixed level (ranging between $0.0 \mathrm{~m}$ to $5.0 \mathrm{~m}$ below the ground surface for each condition) over the whole catchment and running the model for 48 hours to allow the soil moisture regime to stabilise. The synthetic radar data were then sampled at increasingly coarser resolutions: $500 \mathrm{~m}, 1 \mathrm{~km}$, $2 \mathrm{~km}, 5 \mathrm{~km}, 10 \mathrm{~km}$ and $20 \mathrm{~km}$ (i.e. over the whole catchment) and fed into the model, again for each initial soil

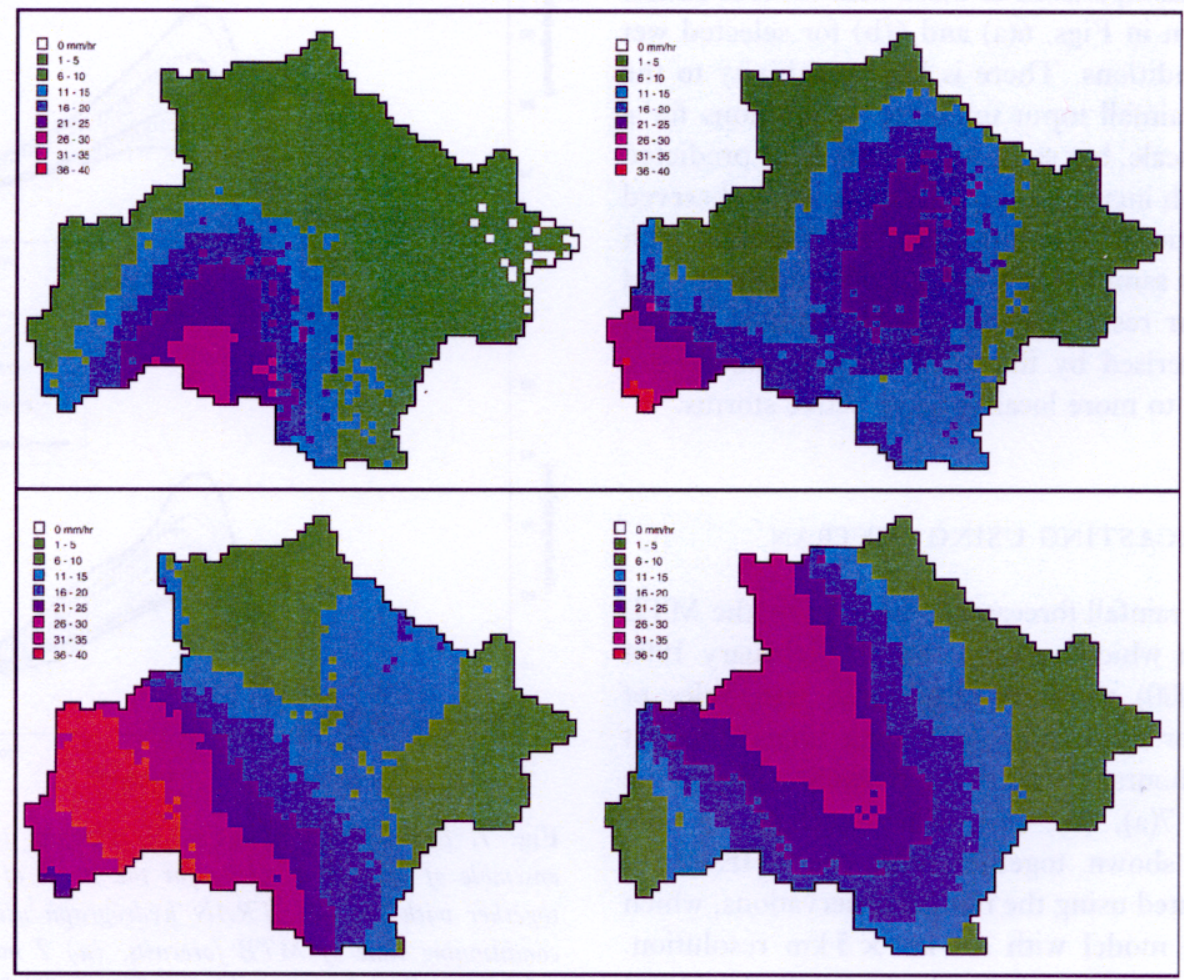

Fig. 5. (a)-(d). A typical incoming storm. 

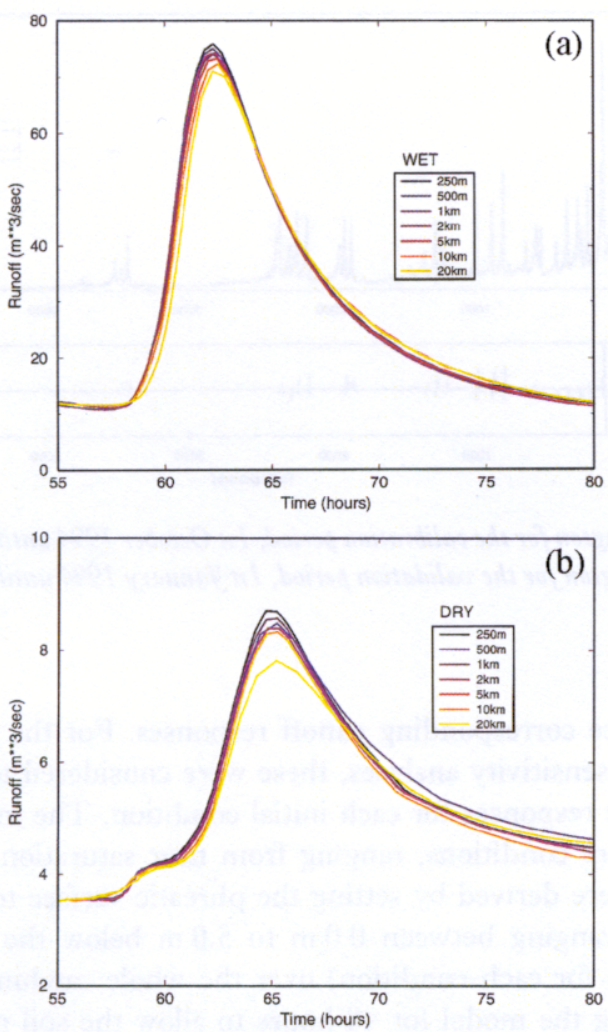

Fig. 6. Effect of spatial resolution of rainfall input on runoff response: (a) met-phreatic surface level $0.0 \mathrm{~m}$ below ground, (b) dry-phreatic surface level $2.0 \mathrm{~m}$ below ground.

moisture condition, to produce a set of corresponding runoff responses. Comparisons of these with the true runoff response are shown in Figs. 6(a) and 6(b) for selected wet and dry initial conditions. There is little sensitivity to the averaging of the rainfall input under wet conditions for a catchment of this scale, but some reduction in the predicted peak responses with increased rainfall averaging is observed under 'dry' conditions. The procedure was repeated with real radar data with sampling resolutions of $5 \mathrm{~km}, 10 \mathrm{~km}$ and $20 \mathrm{~km}$, with similar results. These results apply to frontal storms, as characterised by the MTB model, and do not necessarily extend to more localised convective storms.

\section{ENSEMBLE FORECASTING USING SHETRAN}

The ensembles of rainfall forecasts, generated by the MTB model for a storm which occurred on $3^{\text {rd }}$ February 1994 (Mellor et al., 2000) were converted into ensembles of runoff forecasts for different conditioning times (forecast origins) of $-2,0,2$ hours relative to the storm first hitting the catchment (Figs. 7(a), (b), (c)). The envelope of each ensemble is also shown together with the SHETRAN hydrograph simulated using the rainfall observations, which were fed into the model with a $5 \mathrm{~km} \times 5 \mathrm{~km}$ resolution. Therefore, the comparison of this hydrograph, simulated from the observed rainfall, with the ensemble of runoff forecasts allows an assessment of the performance of the MTB rainfall forecasts, since any error associated with the rainfall-runoff model has been eliminated.

For each forecast origin, the envelope includes the peak of the observed rainfall hydrograph. The envelope includes all the observed rainfall hydrograph for the 0 hour forecast origin, but parts of the observed rainfall hydrographs lie slightly below the envelopes for the other two forecast origins. However, the envelope is narrower if the forecast is made later in the storm.

These results are consistent with the observed rainfall intensity and the envelopes of rainfall intensity scenarios
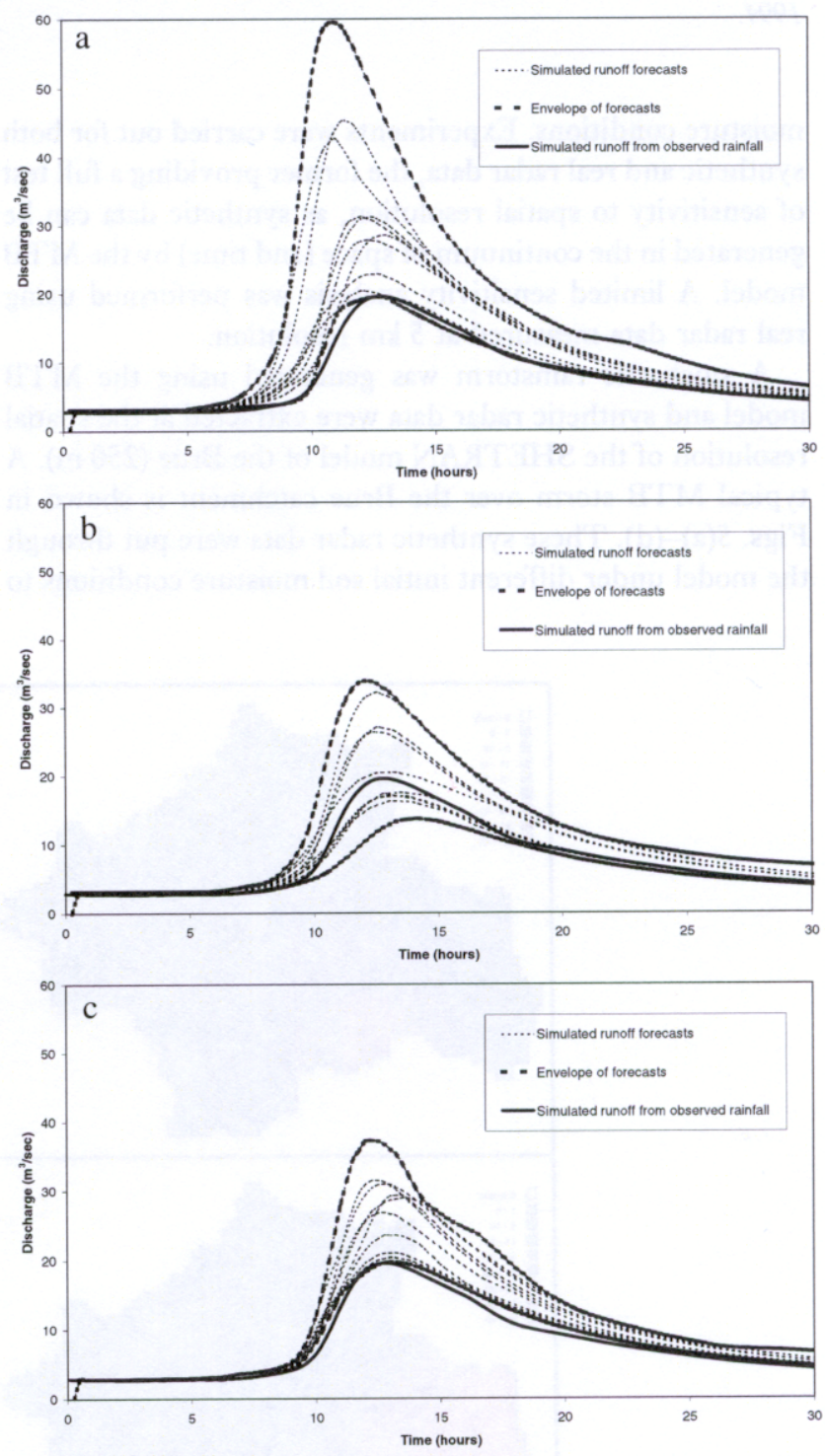

Fig. 7. Envelope of SHETRAN responses to the MTB forecast ensemble of rainfall scenarios for the storm of 3rd February 1994, together with the SHETRAN hydrograph using observed rainfall: conditioning time of MTB forecasts, (a) 2 hours before storm hits catchment, (b) when storm hits catchment, (c) 2 hours after storm hits catchment. 
generated by the MTB model (Mellor et al., 2000) Figs. 9a, $b, c)$. The rainfall scenarios generated by the MTB model exhibit the high frequency variation which is a physical feature of rainfall during storms. The rainfall-runoff model filters out the high frequency variation to produce smooth hydrographs in a physically realistic manner. In Fig. 9a of Mellor et al. (2000) for example, the area under the observed rainfall intensity curve is closest to the smallest of the areas under the simulated scenarios, all of which exceed substantially the lower boundary of the envelope during parts of the storm. This becomes more apparent after the smoothing which results from passing the storm profiles through the rainfall-runoff model.

\section{Application of ARNO model to the Brue catchment}

\section{THE ARNO MODEL STRUCTURE}

The ARNO rainfall-runoff model (Todini, 1996) was originally developed as part of a real time flood forecasting system for the River Arno, and has since been used widely for flood forecasting and other applications. It is a semidistributed conceptual model with two main components. The first describes the soil moisture balance, and the second describes the transfer of runoff to the outlet of the basin. A typical large catchment is divided into a series of subcatchments but, based on the results obtained above on the sensitivity of the SHETRAN response to the averaging of the rainfall input, it was not considered necessary to break down the Brue catchment into sub-catchments for ARNO modelling purposes. The catchment was therefore treated as a single unit with a spatially averaged rainfall input.

The main physical phenomena represented in the ARNO model are: water balance in the soil, water losses through evapotranspiration, snow melt, overland flow, groundwater flow and, finally, the channel flow routing. These aspects of the model have been developed as inter-linked modules. The soil moisture balance is determined by dividing the catchment into elements of area which are classified as pervious or impervious, and then assuming (after Zhao, 1977) that a distribution function can describe the proportion of the pervious area that is saturated. A similar concept has been developed by Moore and Clarke (1981, 1983). The evapotranspiration is assumed to depend on: crop, wind speed, temperature, altitude, extraterrestrial radiation and the proportion of sunshine. The extraterrestrial radiation is available from tables as a function of latitude. The calculation of evapotranspiration is based on a simplified form of the Penman-Monteith equation (Doorembos et al., 1984).

\section{ARNO MODEL IMPLEMENTATION ON THE BRUE}

The data requirements for the ARNO model are less extensive than for the SHETRAN model. It requires: topographic data (hillslope and channel slopes); precipitation, temperature and river levels at several stations within the catchment; soil type and land use data; and rating curves for the hydrometric stations where the discharge is to be simulated (in the case of the Brue, the outflow point at Lovington). Some of the parameters can be determined from the above data, but most of them have to be determined by trial and error. However, this is a relatively straightforward process since the model parameters have clearly defined effects on catchment response. In this application, with only one unit, the ARNO model is a rather rough approximation to the catchment, but $R^{2}$ goodness of fit values of 0.88 and 0.80 were obtained for the same calibration and validation periods used with SHETRAN. This indicates that comparable results can be obtained with the simpler lumped model, albeit with a slight drop in performance during the validation period. Plots of simulated and observed discharge for the calibration and validation periods are presented in Figs. 8(a) and (b).

\section{ENSEMBLE FORECASTING USING ARNO}

The responses of the ARNO model to the forecast ensemble
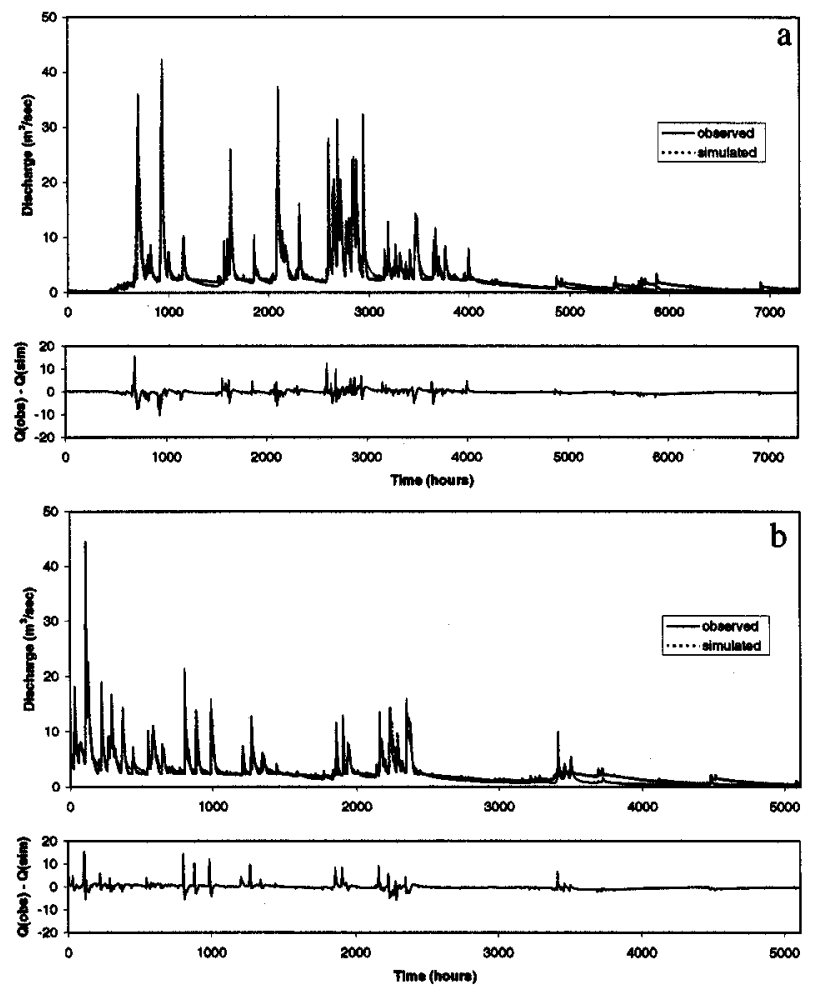

Fig. 8. (a) ARNO simulated outlet discharge, and observed discharge, at Lovington for the calibration period, 1st October 1994 until 31st fuly 1995. (b) ARNO simulated outlet discharge and observed discharge, at Lovington for the validation period, Ist fanuary 1994 until 31st Fuly 1994. 

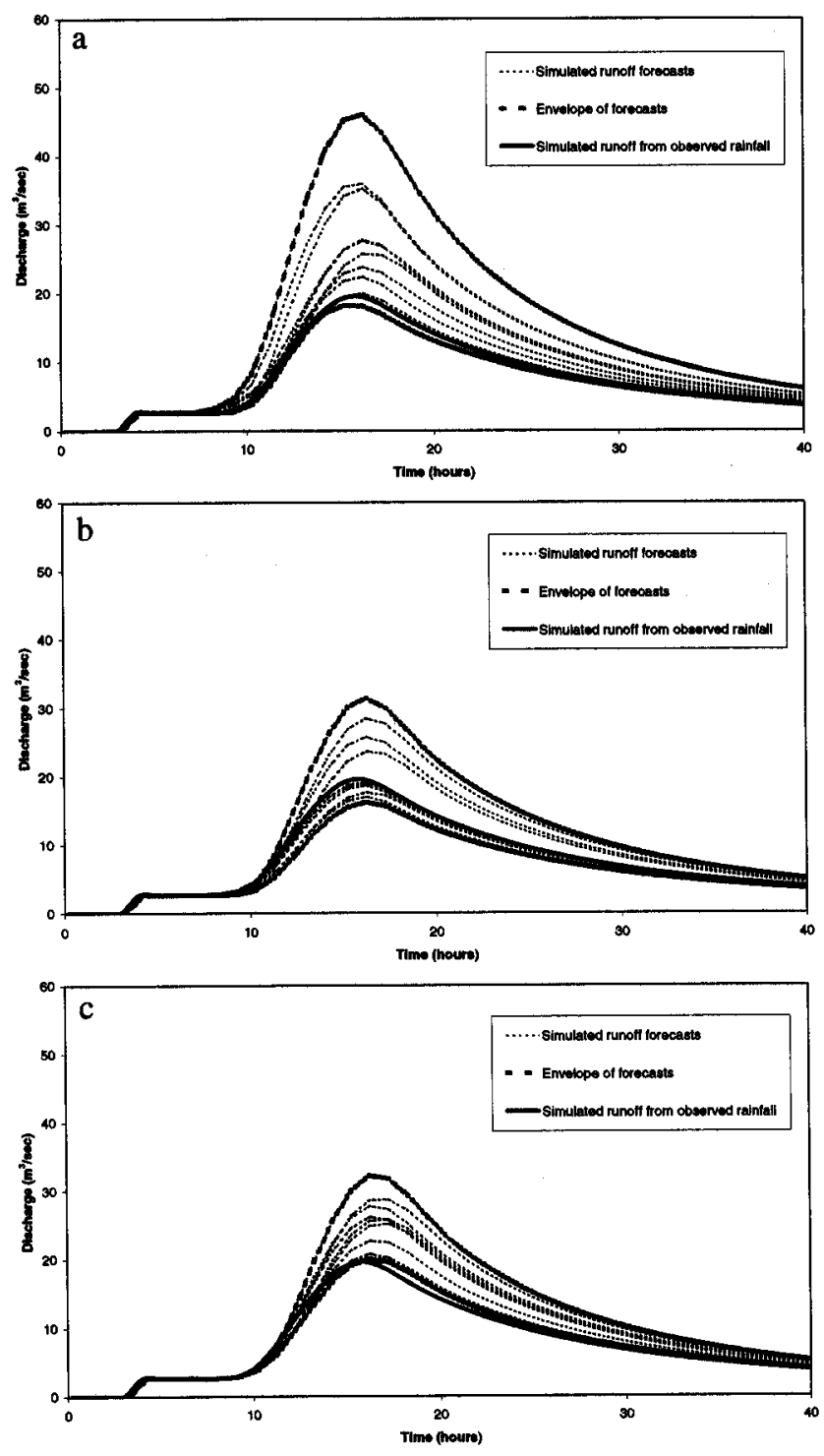

Fig. 9. Envelope of $A R N O$ responses to the $M T B$ forecast ensemble of rainfall scenarios for the storm of 3rd February 1994, together with the SHETRAN hydrograph using observed rainfall: conditioning time of $M T B$ forecasts, (a) 2 hours before storm hits catchment, (b) when storm hits catchment, (c) 2 hours after storm hits catchment.

of scenarios are shown in Figs. 9(a), (b) and (c). They are qualitatively similar to those from the SHETRAN model, but the envelope for the ARNO model is rather narrower and noticeably lower at the peaks: 47,32 and $33 \mathrm{~m}^{3} \mathrm{~s}^{-1}$ for the ARNO model at $-2,0,+2$ hours respectively, compared with 59, 34 and 38 for the SHETRAN model. This is consistent with the smoothing effects of lumping. Nonetheless, the results indicate that ensemble forecasting with the MTB model deserves further exploration as a realtime forecasting tool.

\section{Discussion and conclusions}

\section{ASSESSMENT OF ENSEMBLE FORECASTS}

There are two issues to be discussed here. The first is whether the claimed prediction limits ( $90 \%$ for example) are valid. The second concerns the comparison of different forecasting systems on the basis of valid $90 \%$ prediction limits. A reasonable criterion for selecting the best system would be that with the narrowest valid prediction limits. A method for assessing the validity of prediction limits follows.

The probability that a hydrograph, generated by a known stochastic mechanism, will be outside an envelope of $n$ hydrographs, generated by the same mechanism, in at least one place could be found by simulation. However, it is not clear how this probability would be incorporated into a practical decision support framework. A more useful criterion would be whether some crucial feature such as flood peak, or flood volume, is consistent with the range of flood peaks, or volumes, for the individual scenarios. For example, an ensemble of 10 rainfall scenarios, and hence 10 hydrograph scenarios, could be generated at the approach of a storm, and the maximum of the 10 hydrograph peaks could be used as a forecast for flood warning purposes. About nine per cent of actual flood peaks would be expected to exceed such forecasts, ( $9 \%$ corresponding to a plotting position of $i /(n+1))$. Many storms would be needed to check the validity of this $9 \%$ figure directly but an alternative method, described below, would be practical with a substantially smaller number of storms.

This method requires that a large number of rainfall scenarios, 100 for example, be produced at the time a forecast is made. The scenarios can be simulated quickly once the MTB model has been fitted. The first 10 rainfall scenarios might be run through the rainfall-runoff model immediately to generate an ensemble of hydrographs, as part of the forecasting procedure. The other 90 scenarios could be run through the rainfall-runoff model later, to give an ensemble of 100 hydrographs. The 100 hydrograph peaks are sorted from smallest to largest, and given a rank number from 1 to 100 . The rank of the scenario peak closest to the observed peak is noted. This procedure would be carried out with approximately 20 storms. If the prediction limits are valid, the distribution of the ranks associated with the observed peaks should have a uniform distribution over $[0,101]$. This could be tested using the KolmogorovSmirnov test.

\section{SENSITIVITY OF CATCHMENT RESPONSE TO SPATIAL RESOLUTION OF RAINFALL INPUTS}

It was expected that any sensitivity to spatial averaging would be related also to the soil moisture conditions of the catchment. There are convincing physical reasons for this. 
If the catchment is already saturated, most of the rainfall will flow overland into the rivers because the saturated soil cannot absorb any more water (saturation excess). Intense rain over a small area could lead to a sharper hydrograph with a higher peak than the same volume over a larger area. However, as the size of the raincells is of the order of 10 $20 \mathrm{~km}$, this effect, although apparent, is not significant for the majority of scales of averaging used here. At the smaller scales, the spatial pattern of rainfall is near enough preserved and thus so are the areas of runoff production. It is only when rainfall is sampled at scales which approach the size of the raincells, i.e. $10-20 \mathrm{~km}$, that the reduction in runoff response might be significant. Repetition of these experiments for catchments larger than the Brue is required to investigate fully any such effect, where large sampling scales, relative to the raincell size, can be tested.

A drier soil has a greater capacity to accept infiltrating water. Heavy localised rainfall can lead to runoff production from locally saturated areas, whereas a larger proportion of the total volume would infiltrate into the soil if the rainfall were averaged over the catchment. It is also possible for intense rainfall to be so heavy that it falls at a faster rate than the infiltration rate into the soil. Then overland flow occurs before the soil becomes saturated. However, this is unlikely to occur in the UK. The SHE model has been demonstrated to exhibit the former effect. When the phreatic surface level (psl) is $0.0 \mathrm{~m}$ (Fig. 6a), the peak flow with $20 \mathrm{~km}$ resolution is $8 \%$ less than that with $250 \mathrm{~m}$ by $250 \mathrm{~m}$ squares. In contrast, when the psl is $2.0 \mathrm{~m}$, corresponding to dry initial conditions, the peak flow with $20 \mathrm{~km}$ resolution is $17 \%$ less than that with $250 \mathrm{~m}$ squares. The absolute reductions in peak flows when moving from $250 \mathrm{~m}$ to $1 \mathrm{~km}$ squares are considerably less, $3 \%$ and $6 \%$ for psl of $0.0 \mathrm{~m}$ and $2.0 \mathrm{~m}$ respectively, but the relative difference in reduction between wet and dry initial ground conditions is still a factor of two. It is interesting to compare these results for frontal rain over a catchment in the South-West of England, with those obtained for thunderstorms over a semi-arid catchment at Walnut Gulch in Arizona by Michaud and Sorooshian (1994); they found that the effect of averaging data from a very dense network of raingauges $\left(1\right.$ per $\left.\mathrm{km}^{2}\right)$ over $4 \mathrm{~km}$ squares was to reduce the peak flow by an average of $34 \%$. The difference in degree can be attributed primarily to the differences between frontal and convective rainfall.

Although the effect of averaging a rainfall field over increasingly large grid squares has been investigated, the total volume for each grid square is unchanged. This is quite distinct from the effect of replacing these spatial averages by values at a point within the squares, as happens if raingauges are used instead of radar. These sampling issues have been considered by several authors, and networks of raingauges may miss storms, which would be detected by radar. Furthermore, the essential features of radar, which cannot be replaced easily by a system of raingauges, are the facilities to track the approaching storm and resolve the structural features and their velocities. This information is needed for the MTB method of producing rainfall scenarios.

\section{Conclusions}

The following conclusions can be synthesized from this research.

1. The viability of ensemble rainfall forecasting using the MTB rainfall field model has been demonstrated.

2. Based on experiments with SHETRAN and the MTB model, the sensitivity of catchment response/runoff forecasts to spatial averaging of the rainfall input is limited under wet catchment conditions and more significant under dry conditions; these results relate to frontal storms and catchments similar to the Brue.

3. The envelope of ensemble flow forecasts generated by SHETRAN was found to include the peak and most of the response generated by the observed rainfall input for a selected storm for all of the forecast time origins.

4. The hydrographs obtained by passing the observed rainfall through the ARNO and SHETRAN rainfallrunoff models are very similar. However, the ensemble of peaks simulated with different MTB scenarios is narrower using the lumped ARNO model rather than the distributed SHETRAN, for the event investigated. The most likely explanation is that the ARNO model introduces too much smoothing and hence reduces somewhat the variability of the hydrographs. This need not necessarily reduce the value of the ARNO model for operational use. For example, it may be feasible to use the maximum peak of 20 hydrographs from the ARNO instead of the maximum of 10 from the SHETRAN for flood warning purposes. Mean and median peak values from the two models should be very similar.

\section{References}

Abbott, M.B., Bathurst, J.C., Cunge, J.A., O'Connell, P.E. and Rasmussen, J., 1986. An introduction to the European Hydrological System-Système Hydrologique Européen, 'SHE', 2: Structure of a physically-based distributed modelling system. $\mathcal{F}$. Hydrol., 87, 61-77.

Bras, R.L., Tarboton, D.G. and Puente, C., 1988. Hydrologic sampling: a characterisation in terms of rainfall and basin properties. 7. Hydrol., 102, 113-135.

Doorembos, J., Pruitt, W.O., Aboukhaled, A., Damagnez, J., Dastane, N.G., van den Berg, C., Ritjema, P.O., Ashford, O.M. and Frere, M., 1984. Guidelines for predicting crop water requirement. FAO Irrig. Drainage Pap., 24.

Goodrich, D.C., 1990. Geometric simplification of a distributed rainfall-runoff model over a range of basin scales. Ph.D. dissertation, University of Arizona, Tucson.

Krajewski, W.F., Lakshmi, V., Georgakakos, K.P. and Jain, S.C., 1991. A Monte Carlo study of rainfall sampling effect on a distributed catchment model. Water Resour. Res., 27, 119-228.

Mellor, D., Sheffield, J., O'Connell, P.E. and Metcalfe, A.V., 2000. A stochastic space-time rainfall forecasting system for real time flow forecasting I: Development of MTB conditional rainfall scenario generator. Hydrol. Earth System Sci., 4, 603-615.

Michaud, J.D. and Sorooshian, S., 1994. Effect of rainfall- 
sampling errors on simulations of desert flash floods. Water Resour. Res., 30, 2765-2775.

Milly, P.C.D. and Eagleson, P.S., 1988. Effect of storm scale on surface runoff volume. Water Resour. Res., 24, 620-624.

Moore, R.J. and Clarke, R.T., 1981. A distribution functionapproach to rainfall runoff modelling. Water Resour. Res., 17, 1367-1382.

Moore, R.J. and Clarke, R.T., 1983. A distribution functionapproach to modelling basin sediment yield. F. Hydrol., 65, 239257.

Nash, J.E. and Sutcliffe, J.V., 1970. River flow forecasting through conceptual models. 1: A discussion of principles. F. Hydrol., 10, 282-290.

Obled, Ch., Wardling, J. and Beven, K., 1994. Re sensitivity of hydrological models to spatial rainfall patterns: on evaluation using observed data. 7. Hydrol., 159, 305-333.

Rawls, W.J. and Brakensiek, D.L., 1989. Estimation of Soil Water Retention and Hydraulic Properties. In: Unsaturated Flow in Hydrologic Modelling, Theory and Practice, H.J. Morel-Seytoux (Ed.), Kluwer Academic Publishers, 275-300.

Shah, S.M.S., O'Connell, P.E. and Hosking, J.R.M., 1996. Modelling the effects of spatial variability in rainfall on catchment response. Experiments with distributed and lumped models. F. Hydrol., 175, 89-111.

Todini, E., 1996. The ARNO rainfall model. 7. Hydrol., 175, 339382.

Zhao, R.J., 1977. Flood forecasting method for humid regions of China. East China College of Hydraulic Engineering, Nanjing, China. 